\title{
Relatives' experiences with abuse and neglect in Norwegian nursing homes. A qualitative study
}

\author{
Susan Saga ${ }^{1 *}$, Lene Elisabeth Blekken ${ }^{1}$, Sigrid Nakrem ${ }^{1}$ and Astrid Sandmoe ${ }^{2}$
}

\begin{abstract}
Background: Elder abuse in nursing homes $(\mathrm{NH})$ is a widespread and complex problem. Residents' ability to share their experiences are impeded, due to a high degree of cognitive problems and frailty, and previous studies are thus mainly based on reports from staff. Therefore, we aimed to give voice to the residents by investigating their relatives' experiences with elder abuse in $\mathrm{NH}$.

Methods: Qualitative individual interviews were conducted with 16 relatives of residents with experience of abuse and/or neglect in $\mathrm{NH}$. Content analysis was used to analyse the data.

Results: Relatives perceived neglect as most pervasive and staff-to-resident psychological abuse as a key problem. Physical abuse was mostly related to resident-to-resident aggression. Relatives perceived elder abuse in $\mathrm{NH}$ to be related to low competence among staff, low staffing, poor NH leadership, working cultures characterized by fear and loyalty to employer or co-workers, and a lack of individualized care for the residents. Furthermore, relatives themselves experienced maltreatment from NH, which caused them to suffer stress, anxiety and distrust. Relatives also expressed a need to compensate for lack of care.

Conclusions: Relatives of $\mathrm{NH}$ residents who had experienced abuse reported that neglect of basic care and individual rights was predominant and viewed organizational explanations as most important. Relatives perceive themselves as collaborators in care and are emotionally attached to their family member. Therefore, if relatives experience resident abuse or neglect, it inflicts a feeling of being mistreated themselves, particularly if they are not listened to or their notice of abuse on the part of the resident is ignored or trivialized. Including relatives in a committed partnership with $\mathrm{NH}$ in care practices is not only a valuable path to reduce the risk of abuse, but it also leads to a more sustainable healthcare with high standards of quality and safety.
\end{abstract}

Keywords: Nursing home, Long-term care, Relatives, Next of kin, Elder abuse, Neglect, Qualitative, Interview, Staffto-resident abuse, Resident-to-resident abuse

\section{Background}

Nursing homes $(\mathrm{NH})$ are settings for long-term medical treatment and nursing care for the frail older persons in our society, and at the same time a home where the

\footnotetext{
* Correspondence: susan.saga@ntnu.no

'Department of Public Health and Nursing, Faculty of Medicine and Health Sciences NTNU, Norwegian University of Science and Technology, Trondheim, Norway

Full list of author information is available at the end of the article
}

residents spend the last phase of their lives. Hence, $\mathrm{NH}$ are expected to provide quality care, complying with the human dignity of the resident, and collaboration, honesty, and mutual confidence that ties together families and staff [1]. Still, a growing amount of research has revealed that abuse and neglect frequently occur in $\mathrm{NH}$ in many countries [2-10], including Norway [11-13]. The World Health Organization (WHO) recognizes elder

(c) The Author(s). 2021 Open Access This article is licensed under a Creative Commons Attribution 4.0 International License, which permits use, sharing, adaptation, distribution and reproduction in any medium or format, as long as you give appropriate credit to the original author(s) and the source, provide a link to the Creative Commons licence, and indicate if changes were made. The images or other third party material in this article are included in the article's Creative Commons licence, unless indicated otherwise in a credit line to the material. If material is not included in the article's Creative Commons licence and your intended use is not permitted by statutory regulation or exceeds the permitted use, you will need to obtain permission directly from the copyright holder. To view a copy of this licence, visit http://creativecommons.org/licenses/by/4.0/. The Creative Commons Public Domain Dedication waiver (http://creativecommons.org/publicdomain/zero/1.0/) applies to the data made available in this article, unless otherwise stated in a credit line to the data. 
abuse and neglect as a global public health problem [14], with a range of serious health consequences, including increased risk of morbidity, hospital admissions, institutionalism, and mortality [15-17], in addition to violations of human rights, dignity and well-being of the older person [15].

The WHO defines elder abuse as: "a single or repeated act, or lack of appropriate action, occurring in any relationship where there is an expectation of trust which causes harm or distress to an older person" ([18], p.3). Five types of abuse are generally recognized: physical, psychological, financial, sexual, and neglect [19]. The type of abuse is further categorized according to the relationship between the key stakeholders, and in $\mathrm{NH}$, it is often divided into staff-to-resident abuse [11, 12, 20], family-to-resident abuse [21], and resident-to-resident aggression [22-24].

\section{Prevalence of elder abuse in $\mathrm{NH}$}

A systematic review and meta-analysis of the prevalence of elder abuse in institutional settings suggested an overall abuse estimate of 64\% [20]. This estimate was based on $\mathrm{NH}$ staff reports of abuse of patients for 1 year. Prevalence estimates for abuse subtypes as reported by residents themselves were highest for psychological abuse (33\%), followed by physical (14\%), financial (14\%), neglect (12\%), and sexual abuse (2\%) [20]. A Norwegian cross-sectional study of elder abuse in $\mathrm{NH}$ found that among the 3693 nursing staff who participated in the study, $60 \%$ reported they had perpetrated one or more incidents of abuse during the past year [12]. Psychological abuse and neglect had the highest prevalence, at 40 and $47 \%$ respectively. Physical abuse was reported by nearly $10 \%$, while most staff in this study reported that they had never committed financial or sexual abuse.

$\mathrm{NH}$ residents are also exposed to abuse from coresidents. In a prevalence study, $20 \%$ of residents had been involved in at least one incident of resident-toresident aggression during a one-month observation period [22]. In Norway, a survey of staff observing resident-to-resident aggression found that nearly $90 \%$ had observed one or more incidents of aggression between co-residents during the past year [13]. Lastly, there is a lack of prevalence studies related to elder abuse committed by family members and/or close friends inside the $\mathrm{NH}$.

\section{Risk factor or determinants of elder abuse in $\mathrm{NH}$}

Descriptions of elder abuse reveal that determinants for abuse and neglect in the $\mathrm{NH}$ context are complex and multifactorial [25]. An often-used theoretical model is the ecological model, where determinants of abuse and neglect are divided into five levels: individual, relational, institutional, societal, and the chronosystem, with a dynamic relationship between the coparticipants in contexts at several levels [25]. Factors at each of the five levels can either increase the risk of abuse and or be proactive, thus reducing the risk of vulnerability to abuse.

On an individual level, it is recognized that residents in $\mathrm{NH}$ may be particularly vulnerable to abuse and neglect. This vulnerability stems from cognitive impairment, behavioural abnormalities, and/or physical impairments [3]. Studies have reported higher rates of physical abuse in residents with dementia and those with physical impairment $[24,26]$. Further, certain staff characteristics are also predisposing for elder abuse in $\mathrm{NH}$ at an individual level. Wang et al. [27] found that staff who were younger, less educated, lacking specific training, and perceived a greater burden in their work displayed a tendency towards more abusive behaviours. In addition, stress and burnout have been identified as determinants related to staff characteristics $[10,28,29]$.

On a relationship level, staff who experience conflicts with residents, such as managing residents who are unwilling to undress or those who have aggressive behaviour, are more likely to admit to having abused a resident [10]. Other studies have reported a stressful relationship between caregiver and resident to be a determinant for abuse [21, 30, 31].

At an organizational level, studies indicate that staff members working in urban areas are less likely to commit acts of abuse and neglect of an emotional and physical character than staff in rural areas [32]. Low staff-toresident ratios and high staff turnover have also been found to diminish care quality and are determinants of elder abuse and neglect $[29,33,34]$.

Regarding determinants at a societal level, studies and discourses within law, medicine and social science research prevail. Studies have highlighted ageism, the loss of self-determination and perceptions about how ageism affects the healthcare services that are delivered [35, 36]. At the fifth level, the chronosystem, time will impact multiple levels of potential abuse over time and life span, e.g., the impact of length of $\mathrm{NH}$ residence on the likelihood of abuse occurring [25]. A qualitative study from Sweden found elder abuse to be related to older persons' perceptions of their changing roles at the individual level, in the family and in society [37].

\section{Residents and relatives in $\mathrm{NH}$}

In Norway, approximately 39,600 residents, which is approximately $13 \%$ of the population over 80 years, live in $\mathrm{NH}$, and mean age of residents is 85 years [38]. Approximately $80 \%$ of residents have dementia, and most have significant deficiencies in activities of daily living (ADL). $\mathrm{NH}$ have nurses on duty $24 \mathrm{~h}$ a day, and the staff comprises registered nurses, licensed practical nurses and 
unskilled labour. Additionally, an employed physician has the medical responsibility for the $\mathrm{NH}$ residents but is only available a few hours a week [39]. In Norway, the municipalities have a statutory obligation to provide $\mathrm{NH}$ services to those who need it [40]. Most Norwegian NH are owned and run by the municipalities and financed by taxes and resident payment. However, there are also some private non-profit and for-profit providers [39]. Laws and regulations provide a common legal framework for how $\mathrm{NH}$ in Norway are managed and organized, securing a relatively homogenous public service across the country [40]. Consequently, all $\mathrm{NH}$ are accounted for and subject to governmental control.

Due to the high degree of cognitive problems in this population, using residents as informants in studies of elder abuse is usually a challenge [21]. An alternative way to give voice to the residents is through next of kin [41]. Generally, relatives know well the life history of their older family members, the way they have lived and how they have maintained their dignity and self-respect. Research indicates that relatives are capable observers of suspected abuse and neglect and are willing to speak quite frankly if they are not linked to any specific institution or area; thus, they may act as effective proxies for older residents [41, 42]. A Swedish study that explored relatives' perceptions of elder abuse in $\mathrm{NH}$ found that abuse was viewed as a violation of an older person's identity [41]. This was related to staff's failure to take into consideration the knowledge of relatives regarding the resident's appearance, daily routines, and preferred activities in daily life within the institution.

Studies of relatives' involvement in issues of resident dignity, integrity or well-being stress the necessity for staff to build trust and relationships with relatives to ensure that the resident's voice is considered [41-45]. In a Dutch study of end-of-life care in $34 \mathrm{NH}, 252$ family members reported unpleasant experiences such as neglect and lack of respect for the patient [46]. In a Canadian study, family members experienced that resident-to-resident abuse was largely normalized by the institutional context it occurred in [47].

None of the studies presented above investigated direct experiences and perception of abuse and neglect in $\mathrm{NH}$ experienced by residents or their relatives. Therefore, the study aimed to explore the relatives' experiences with elder abuse in $\mathrm{NH}$.

\section{Methods}

In the present study, we explored how relatives experience abuse and neglect of residents in $\mathrm{NH}$ using a qualitative design. Qualitative methods give insight into human practice, experiences, thoughts, expectations, motives and attitudes, and strengthen our understanding of why people act the way they do [48]. The study is part of a larger study funded by the Research Council of Norway (NFR) (Project Number 262697).

\section{Setting/sample}

We posted information about the study on the social media platforms of collaborative private non-profit organizations, the Norwegian Centre for Violence and Traumatic Stress Studies (NKVT) and the Norwegian University of Science and Technology (NTNU). Relatives contacted the researchers for an interview. The inclusion criteria were close relatives of $\mathrm{NH}$ residents who had experienced abuse or neglect and: 1) were or had been close relatives of an older resident in a $\mathrm{NH}$ for at least 1 year, and 2) that it was no longer than 5 years since they were close relatives of a resident in a $\mathrm{NH}$. In addition, the snowball method was used in the sense that we asked informants whether they knew of others who fitted the study criteria. The informant then contacted the potential new informant with information about the study and reported back to the researcher if the potential new informant agreed to participate.

The recruitment and data collection were conducted simultaneously during a two-month period. We used a purposive recruitment strategy and included informants that could cover the aims of the study [48]. The inclusion of new informants was based on continual assessments of the themes and conceptual depth that emerged from initial analysis of the interviews. We stopped recruitment of new informants when we considered that saturation was attained in the collected datasets. Thereby establishing an inductive thematic saturation [49]. The final sample consisted of two men and 14 women, a total of 16 relatives (Table 1). Geographically, informants were recruited from all regions of Norway and both urban and rural areas. The informants were ethnic Norwegians and were all working, except two retired informants. The informants worked or had worked

Table 1 Informant characteristics

\begin{tabular}{ll}
\hline Informants $\boldsymbol{n}=\mathbf{1 6}$ & \\
\hline Gender (numbers) & 2 \\
$\quad$ Male & 14 \\
Female & \\
Age (Years) & $59(49-72)$ \\
$\quad$ Mean (range) & \\
Relation to nursing home resident (number) & \\
$\quad$ Wife & 12 \\
Daughter & 2 \\
Son & 12 \\
Length of stay in NH for parent/spouse (years) & \\
Mean (range) & $4(1-10)$ \\
\hline
\end{tabular}


in health care, social care, academia/education, design, engineering, public transportation, as leaders, as business office clerk, and as self-employed in business.

\section{Data collection}

Data for this study were collected by individual, semistructured in-depth interviews [48]. The interviews were carried out in April-June 2020. Due to the COVID-19 situation and sudden lockdown of society in Norway, the interviews were conducted by telephone. All interviews were conducted one-to-one with the informants by SS, LEB and AS. The interviewers are all researchers with PhD's and have long experience in conducting research interviews. An interview guide with open-ended questions was used (Table 2). The interview guide was piloted in a focus group and enhanced according to their comments. To obtain an information-rich description of the informants' experiences, a narrative approach was used for the interviews, encouraging the informants to freely talk about their experiences as relatives [48, 50]. During the interview, the interviewer repeated and summarized the expressions of the informants and asked them whether it was correct. The interviews were audiorecorded and transcribed verbatim, retaining frequent repetitions, pauses and emotional expressions. The quotes used in the manuscripts were rewritten into full sentences in order to retain the full meaning of the expressions. Transcripts were reviewed upon completion by the first and second authors to ensure that they reflected the content of the interviews. Each interview lasted for $50-90 \mathrm{~min}$.

\section{Analysis}

Graneheim and Lundman's [51, 52] manifest and latent content analysis was used to analyse the data. The interviews were read in their entirety by the first and second authors to get an overview. The process of looking for meaning and patterns in the data began during the first reading by marking text in the transcripts and writing short keywords. Thereafter, work began to identify units with an independent meaning in relation to the research question. These meaning units were condensed and subsequently coded. The tool MindManager 2020 was used to code the data material and abstract into sub-themes and themes. By moving on to sub-themes and themes, we moved from the manifest to the latent content of the text by describing an interpretation of the underlying meaning [51, 52]. To ensure that the analysis was performed reliably, the coding process was performed by two researchers independently (SS and LEB). During this phase, they met for a critical review and discussion of preliminary codes, sub-themes and themes. Further, three selected transcripts were read by two more researchers ( $\mathrm{SN}$ and AS) before a joint analysis meeting where coding and preliminary themes were presented and discussed to reach an agreement. The first author then critically assessed codes, sub-themes, themes, and selected quotes to examine whether they provided a representative picture of the material.

\section{Ethical considerations}

Ethical approval for this study was given by the Norwegian Centre for Research Data (NSD), Registration No:

Table 2 Interview guide

\begin{tabular}{ll}
\hline Topic & Key questions \\
\hline Introduction & Can you describe what you define as abuse and neglect in nursing homes? \\
Your experiences of abuse and neglect as a relative & $\begin{array}{l}\text { Can you describe your experience of abuse and neglect to the resident of which you are a } \\
\text { relative? } \\
\text { To detect elder abuse and neglect }\end{array}$ \\
& Can you describe how you found out about incidences of abuse and neglect in the nursing \\
& Can you describe the communication with staff or nursing home managers? \\
& Can you describe if there are things that makes it difficult or challenging to report such \\
& incidents?
\end{tabular}

Nursing home management of reported abuse and Can you describe how the nursing home managed the reported/detected incidences of abuse neglect incidences and neglect?

Can you describe what is challenging in such a situation?

Do you dare to be honest when there is something you are not happy with regarding the care of your family member?

The role of relatives to prevent abuse and neglect in nursing homes
Can you describe how you as a relative may contribute to prevent abuse and neglect?

Can you describe how you want your family member's needs to be met in the nursing home?

Can you describe what was important for you to convey about your family member when he or she moved to the nursing home?

Can you describe how you think your family member experiences the events in the nursing home that you have described? 
740981. All participants received oral and written information about the study prior to the interview and NSD approved that the participants could give an oral audiotaped consent to participate in the interviews and for the use of the data from the interviews. All identifiable characteristics are excluded from the presentation of data to ensure the anonymity of all individuals.

\section{Results}

The qualitative interviews focusing on $\mathrm{NH}$ abuse elicited responses in two overarching areas - resident abuse and maltreatment of relatives (Table 3). Firstly, the informants predictably elicited responses on the theme "resident abuse". Secondly and more surprisingly, they described how they as relatives felt subjected to maltreatment from the $\mathrm{NH}$ when asked about their cooperation with the $\mathrm{NH}$.

\section{Resident abuse}

In the "resident abuse" theme, three sub-themes were generated: 1) abuse characteristics as perceived by relatives, 2) how relatives explain elder abuse in $\mathrm{NH}$ and 3) consequences of elder abuse.

\section{Abuse characteristics (Fig. 1)}

Relatives expressed that neglect was perceived as the most common form of abuse in $\mathrm{NH}$ and described neglect more as a rule than an exception. Relatives reported many instances of inadequate grooming related to both appearance and hygiene, and well-being. Relatives reported that residents were not given baths or showers, their skin was not moisturised, their hair was not properly combed, nor were toenails cut: 'And when we take off one shoe, it's full of blood. [...] The nails had curled and gone in. It was absolutely terrible' (informant 13).

Relatives reported that residents were not given proper assistance in toileting. Incontinence pads were not changed, even when this was requested by relatives or the residents themselves. One relative described the experience: '[Mother]...had chronic urinary tract infections. And I told them to change her a lot, so she didn't have to sleep with it. "Oh yes, they would do it," they said. But I groomed her every day when I came in. And I asked many times: "When did you last change her [diaper]?" Then I came in at five o'clock. No, they hadn't changed her during that shift. And she was wet every time I changed her' (informant 11). The informants also experienced poor dental care to the extent that residents lost their teeth or had problems with eating or talking due to poorly attached dentures.

Relatives also experienced that residents received inadequate assistance during meals: 'Eventually, I discovered that they didn't give my mom enough food. If she doesn't eat fast enough, they take away the plate of food and say: "You know, you'll get supper afterwards"' (informant 14). Informants reported that residents received too little food or were being served food they did not like, despite relatives having repeatedly explained such issues to staff.

The informants also addressed issues regarding bedtime routines and nocturnal sleep patterns, for instance, being put to bed for the night too early: 'I came up at six o'clock, and she was put to bed. Then she'll sleep until the next morning and even longer' (informant 7). Several relatives reported similar stories: 'We came to her room, but we hadn't given notice that we were coming. She was lying down. And when we said: "But it's not even three," they replied. "Yeah, but if we close the curtain, she doesn't see the daylight, and she doesn't understand that it's daytime"' (informant 13). Another informant said that the nursing staff turned the resident's hearing aids off at seven so the resident would become sleepy earlier. Also, they did not always assist the residents up from bed in the morning, especially during weekends when there were fewer staff.

Relatives described problems related to the resident's sense of security at the NH. Relatives witnessed that nursing staff did not always respond to alarms or cries for help from residents, and it took a long time before they responded: 'It takes a very long time when she calls for help' (informant 15). Some of the residents were left behind or forgotten by staff or even called relatives at home from their rooms and asked them to notify the $\mathrm{NH}$ that they needed help.

Informants also described instances of inadequate medical treatment and follow-up of existing medical conditions, as well as harm or injuries that occurred after admission: 'She had clearly been injured and cried a lot due to the pain. [...] I wanted an x-ray examination for her. She didn't get it; she was refused medical attention. A week after the fall, she got an x-ray, and it turns out that she had two fractures in her pelvis' (informant 9).

The informants described experiences of psychological abuse, such as ignoring, yelling, ridiculing and offensive

Table 3 Themes and sub-themes

\begin{tabular}{lll}
\hline Theme & Resident abuse & Maltreatment of relatives \\
\hline Sub-themes & Abuse characteristics & Characteristics of relative maltreatment \\
& Explanations for resident abuse & Consequences of relative maltreatment \\
& Consequences of resident abuse & \\
\hline
\end{tabular}




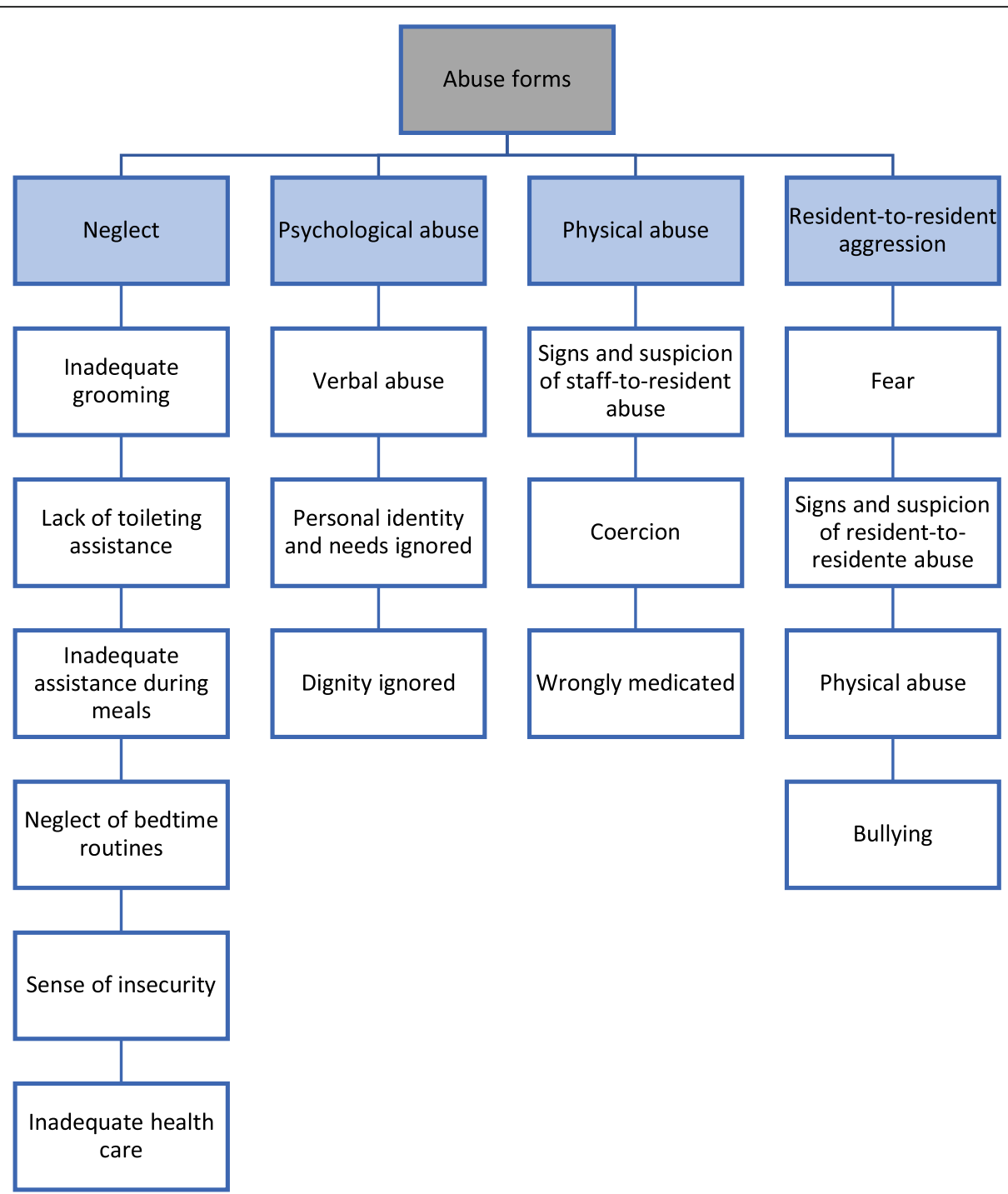

Fig. 1 Examples of abuse forms reported by relatives

communication with the residents: [staff saying]: 'You have to stop fussing. I've just been with you. Now I'm so tired of your fuss' (informant 6). Moreover, relatives also described "hard reality orientation". One informant reported, for instance, how her mother would sit in the wheelchair and say: "Drive me home!" And then they replied: "You have no home"' (informant 5). The relatives expressed that staff sometimes acted in a way that threatened the residents' dignity. For instance, informants reported that staff did not knock on the door before entering the resident's room. Further, residents had to sit with incontinence pads with faeces during meals and together with other residents and their relatives. They also reported that staff spoke loudly and freely about intimate and private subjects in common areas.

In the interviews, informants gave examples where the residents' identity and personal needs were ignored by staff. For instance, several informants referred to situations where staff did not respect the residents' belongings, but loaned them out to other residents without asking, with the result that things disappeared. Individual needs, habits and routines were also being ignored. One informant said the staff were frustrated because her mother would not eat some days. The problem was that the staff kept giving the resident porridge, although the relative had been telling the staff for 2 years that her mother did not like porridge. Another informant talked about her mother: 'But I had written that list. What she liked and what she didn't like and all that. It was posted in her room. And I wrote that she doesn't like red lemonade. You know what ... The day before she died, there's a glass of red lemonade. Then she'd been there for over a year' (informant 11). Relatives explained how they had created clothing strategies for a resident who was blind 
so she could find what she needed, but the staff did not bother to follow up on it. Residents who had been very particular with their clothes and appearance now appeared uncombed and dressed in random clothes.

The informants also reported physical abuse, including situations where residents were subject to heavyhanded approaches by staff during care, leading to suspected bruising or other injuries. When the relatives detected bruises on the residents, the staff did not always know the reason for it: '... I was talking about the bruises. I don't know what's really been going on, but they must have handled her in a hard manner, obviously. There were times when I came where she was going to explain things to me, but she was demented. It wasn't that easy for her to find the words' (informant 3). A few relatives reported suspicion of sexual abuse: 'I've suspected there's been sexual abuse, but I don't have any evidence' (informant 5).

Relatives also expressed how the use of coercion could lead to physical abuse. Residents were physically restrained or not allowed to walk freely: 'I was standing in front of that door to her ward, and I heard her scream. She screams: "Open the door!" I press the button, and the door opens. Then I see a nurse, [...] along with another nurse drag her across the floor. And then I walk over to her, I scream: "What the hell are you doing to my mother?" Right. And then I embrace my mother, my mother [embraced] me. And then, she is calm, and she's crying on my shoulder' (informant 14).

More often, physical abuse of residents was reported as occurring between residents, as these often are residents with dementia: 'There are marks on her, so we ask: "Where did those marks come from?" They said: "It's a resident." There's always a resident. But I haven't seen that other than that I've seen that the one who is violent, she goes and rips things out from their hands while they sit there. It's a pretty rough and big lady' (informant 13). The relatives said that residents pushed, beat, kicked or bullied co-residents. They also had examples where their loved ones feared that other residents could come into their room during the night.

Several relatives reported that residents who feared coresidents due to agitation or abusive behaviour were sedated by staff instead of protecting or secluding them: 'She has been medicated due to co-residents' agitation and violent behaviour because it affected her so much that she became afraid' (informant 10). Informants also reported medical abuse, where residents were given too little pain-relieving medication, with physical pain and withdrawal issues as consequences, in addition to situations of forced medication.

\section{Explanations of elder abuse}

Even though the relatives were not asked directly why they perceived elder abuse happened in $\mathrm{NH}$, they spontaneously expressed a wish and a need to understand why the abuse occurred.

Informants mentioned low staffing as an important explanation for abuse. For instance, the relatives perceived a lack of staff present in living rooms and corridors to detect residents' individual needs and avert potentially harmful situations such as agitation and violence: 'The largest neglect is that there are not enough people to observe these demented people sitting in the big living room' (informant 9). The relatives also expressed that the nursing staff had insufficient expertise, particularly in relation to dementia and how to handle challenges associated with it: 'Is the anomaly that she does it or is the anomaly that the ward and the system are not well enough equipped to prevent her from doing it?' (informant 8). In addition, there are many unskilled workers among the staff: 'They pick people up right off the street, with almost no training, and let them start caring for people with this type of disease' (informant 16). The informants seemed to agree that there was both skilled and unskilled staff who were personally unsuitable for working with frail older residents. However, they also acknowledged that there were staff who cared for the residents and did a great job: 'And that's what I've been most pissed off about, that I think there's so little competence... Not everyone, because there are many wonderful ones here, and I'd like to say that there are so many amazing ones. But there are some cases where you see it is quite frightening, the ones that are there' (informant 6).

An explanation that emerged from the interviews, connected to lack of competence, was the general lack of individualized care and adaptation of care practices. For instance, the mother of one of the relatives had asthma, and inadequate medication for her condition led to breathing difficulties, which in turn caused anxiety and agitation. Furthermore, this resident's agitation also led to anxiety in other residents. Thus, the lack of holistic approaches and the absence of a basic understanding of what caused the resident's behaviour had negative effects for both the resident and her co-residents.

The relatives also pointed to lack of leadership and other organizational challenges as an explanation for elder abuse in NH. They referred to the absence of adequate resident follow-up by an assigned primary nurse, language challenges among immigrant nursing staff, and that issues reported to the $\mathrm{NH}$ were not adequately addressed by unit management. The workplace culture was also highlighted as an important explanation for elder abuse in NH. The relatives talked about staff who would defend themselves or trivialize incidents if they received 
reports of neglect from relatives. The relatives described a fear culture among staff, who were afraid of sanctions from their co-workers or feared losing their jobs. One of the relatives exemplified this with a talk she had with a former nurse of her family member after the family member had been moved to another $\mathrm{NH}$ institution due to a long conflict with the former $\mathrm{NH}$ : 'And then she said: "You know what, I think about that time at [name of NH] when you were there. I couldn't help you. If I tried and the others saw that I helped you or supported you ... They were simply afraid of losing their jobs." [...] She works in the school system now, and she said: "I get sick, I get a stomach-ache when I think about these leaders, and I think about how it was there. And I will never ever work in healthcare again"' (informant 16).

\section{Consequences of elder abuse}

Relatives pointed to deteriorating health in their family members after admission to $\mathrm{NH}$ such as weight loss, teeth falling out, development of bedsores and a vicious cycle where the residents' ADL functions were gradually taken over by staff. Some relatives even believed they were witnessing some sort of euthanasia: 'Active euthanasia is prohibited in Norway, but if one commits a "Sorry, we neglected because we forgot about it", then what is that? You're pushing. You push the resident over the doorstep' (informant 2). The informants told us that residents felt unsafe when they were alone with coresidents, fearful when they woke up at night with a coresident in the room, and insecure when they were exposed to yelling and reality orientation from staff for behaviour the residents themselves did not understand nor comprehend.

Relatives also talked about sadness, depression, resignation, or a feeling of being objectified: 'My husband [the resident] says that: "Eventually I become completely indifferent, or I will perish"' and: 'You become a thing. You're not a human being' (informant 1). One relative said her mother wanted a pill to end it all. The mother of another informant called her daughter every day and cried because she wanted to go home, even though she had been at the $\mathrm{NH}$ for one and a half years. The relatives expressed that unwanted behaviour from the residents, such as agitation and aggression, was a direct result of neglect and abusive communication from staff.

\section{Maltreatment of relatives}

In the "Maltreatment of relatives" theme, two subthemes were generated: 1) Characteristics of abuse of relatives, 2) Consequences of abuse of relatives.

\section{Characteristics of relative maltreatment}

First and foremost, the relatives expressed how their parents' or spouses' suffering was also their suffering: 'And I have suffered so much with him, that what they did to him, they also did to me' (informant 16), and further: 'You leave one that ... whether it is a small child or ... a helpless person in the custody of others, and you constantly walk around insecure and fail to rest assured that ... do they get good care, are they taken care of? So, it's a huge load. At first, it's hard to have them at home, but at the same time, it's so hard to leave them to someone because you're so unsure' (informant 16). Many relatives told how they frequently were barred from involvement in the care of their parent or spouse. They were not told about accidents or incidents, were not getting to meet with staff to discuss the resident, and they did not feel they were listened to, or their advice taken, even though they were the ones who knew the resident best.

Relatives told how they repeatedly talked with staff, and sometimes to the care manager, about the care of their parent or spouse, and how they most often were not listened to: '...through the close contact I had as a relative with other relatives in the $\mathrm{NH}$, and also as head of the resident council at two of the city's $N H$, I received some information, sent by email, in despair, anger and frustration that nothing was done' (informant 2). Relatives experienced direct disregard from staff, and staff who had been told by their care manager not to speak to them after disagreements. They said care managers sometimes denied that incidences reported by relatives had happened, and many relatives experienced rejection and arrogance from staff when these incidences were addressed: 'When we enter the NH, I notice that people, the staff that I have such a good relationship with, they give me a dirty look. I just don't understand anything. They didn't greet me. I sat with my mom for half an hour, and then I thought: "What's going on, what's happening?" (informant 9). Many relatives found it difficult to be assigned the role of "troublesome" relative. They felt it was a struggle to repeatedly ask the staff about their parent or spouse or suggest different approaches towards their parent or spouse. One informant expressed how her feelings of fear for her husband were misinterpreted by the staff: 'But when I was despairing, and I was so scared that he was going to die of side effects, then they said to me: "We don't care that you're mad. You can just be angry because we're the ones in charge"' (informant 16). Relatives experienced that cooperation was on the terms of the $\mathrm{NH}$ and that relatives were unwanted: 'As relatives ... there's a hierarchy here. And as a relative, you're really on the bottom' (informant 16).

\section{Consequences of relative maltreatment}

Relatives expressed a sense of powerlessness regarding the system as a whole - after addressing incidences to staff directly, to care managers and, for many of our informants, also to the County Governor. Relatives 
experienced that things mostly did not improve; instead, they were left with a feeling of sadness and grief, and experienced stress and anxiety reactions: 'And every time I went there at the end, I had to visualize and use exercises to manage to walk in the door. [...]. When I was going to enter the NH, my body almost refused to go inside. [...] It was terribly unpleasant. It was absolutely horrific' (informant 16).

The interviews revealed a pervasive distrust towards how the residents were treated. Consequently, the relatives' distrust made it difficult to have an open and honest dialogue and cooperation regarding the treatment of residents: 'It's not only the good things you want to bring up, but I had never shared my... my thoughts and feelings towards the staff in any meetings. I wouldn't have trusted that they embraced and receive it in a proper way' (informant 10).

Relatives also reported that they feared giving the staff feedback on negative events due to fear of retaliation. Only a few informants mentioned retaliation from the care staff in the form of worsened care for their loved ones. However, most of our informants expressed fear of giving negative feedback: 'And then they will somehow punish Dad. This sounds completely paranoid, but we are afraid that Dad will not get the good care he needs. He can't speak up about his own needs by himself (informant 4).

Relatives expressed how the $\mathrm{NH}$ inadequacy made relatives compensate for lack of care out of fear of what might otherwise happen: 'Had to try to compensate for it. Get up and walk with her when we were there, take her out when the weather was right. Make it nice for her... It was painful. There were awfully many times I left with a lump in my throat' (informant 12). Relatives said they needed to be the voice for the residents who by themselves were unable to explain how they were doing or demand adequate care. Finally, the relatives expressed a deep concern for residents who did not have relatives to actively support them: 'I think if they don't have relatives, how are they supposed to get help?' (informant 13).

\section{Discussion}

This study found that relatives whose loved-one experienced abuse or neglect perceive neglect as most pervasive, and they perceive psychological abuse from staff-toresident as a key problem. Physical abuse was mostly related to resident-to-resident aggression. Relatives perceived elder abuse to be related to low competence and organizational factors such as low staffing, poor $\mathrm{NH}$ leadership, a working culture characterized by fear and loyalty to employer or co-workers, and a lack of individualized care for the residents. The consequences for residents were of a physical, psychological, and existential nature. More unexpectedly, we also found that relatives themselves experienced maltreatment from staff, which caused them stress and anxiety, fear of retaliation from staff towards their parent or spouse, lack of trust, and need to compensate for lack of care.

\section{Abuse forms}

Regarding neglect, we found that relatives whose lovedone's experienced abuse or neglect expressed neglect as the most common form of abuse in $\mathrm{NH}$, and they describe neglect more as a rule than an exception. This is in accordance with findings from a recent Norwegian prevalence study of neglect and abuse as reported by $\mathrm{NH}$ staff [12]. However, in a systematic review of abuse in institutional settings, neglect was less prevalent than psychological abuse, physical abuse and financial abuse [20]. Although our study is not a prevalence study, these patterns seem to contrast with our finding of relatives' experiences of abuse. Our study explored elder abuse in $\mathrm{NH}$ as experienced by people who have themselves witnessed these issues first-hand. The relatives in our study described neglect related to the residents' grooming, dressing, toileting, meals, bedtime routines, sense of security, and healthcare. Buzgovas' descriptions of hygiene and healthcare neglect [21] showed the same as our study. Neglect is linked to the concept of "missed care" [53]. Kalisch [54] and Kalisch et al. [55] viewed missed care as a paradoxical relationship between the theorypractice gaps; nurses knew the appropriate standards of care, yet regularly failed to meet adequate and expected standards of care delivery. Certainly, when aspects of care are neglected, this may result in negative outcomes, including fatalities [56].

Our informants experienced that their loved ones were exposed to psychological abuse, such as yelling, being ignored and ridiculed. They perceived that the $\mathrm{NH}$ did not adequately preserve the resident's dignity and identity. This is in accordance with Buzgova [21], who found "rights violation" as an additional category of "psychological abuse". Dignity is a complex concept that has been linked to identity and associated with respect and autonomy [57]. It can be questioned, however, whether others can assess personal dignity [58], although it has been found that relatives were more able than staff to understand when an older patient's dignity was offended [59]. In two studies, relatives reported that staff did not sufficiently maintain the patient's dignity, rights, and personality/identity $[41,43]$. Therefore, collaboration with close family members is helpful for the complex task of maintaining residents' identity and dignity.

When it comes to physical and sexual abuse, which is reported previously $[12,20,21]$, it seems that this may be a more hidden form of abuse for relatives, since they reported it less frequently in our study. In their 
descriptions of the physical abuse they witnessed, relatives mainly reported co-residents as being the perpetrators. Although physical violence may be considered a serious form of abuse, relatives were not particularly explicit in their descriptions of resident-to-resident aggression. While they did describe incidences and the fear that violent episodes cause in residents, the relatives seemed more concerned about different forms of staffto-resident abuse. Myhre et al. found that $\mathrm{NH}$ leaders perceived resident-to-resident aggression as a "normal part of NH life" [60]. Although relatives in our study are concerned with resident-to-resident aggression and the consequences it has on their family member, their perception of it was similar to the perception of $\mathrm{NH}$ leaders [60]. On the one hand, relatives tend to excuse or accept the occurrence of resident-to-resident aggression; on the other hand, they also expect staff to deal with it. This congruence of perceptions of resident-to-resident aggression between relatives and NH leaders is a problematic aspect highlighted by our study and expresses the lack of awareness of elder abuse in $\mathrm{NH}$.

Our results demonstrate that all forms of elder abuse as defined by the WHO [19] are reported, but relatives reported fewer experiences with financial and sexual abuse. However, the interviews demonstrated suspicions of sexual abuse, and participants reported that belongings were loaned to other residents and disappeared. In our study, the latter has been categorized as psychological abuse due to the lack of respect for personal property, rather than exploitation.

\section{Explanations for abuse}

Findings in our study revealed that relatives whose loved-one's experienced abuse or neglect viewed low competence in staff as an explanation for elder abuse in $\mathrm{NH}$, especially in managing challenges related to dementia, as well as staff unsuitable for working with these residents. These explanations may represent a proxy expression of staff burnout and work overload, known risk factors associated with elder abuse [10, 27-29]. In a study of caregivers' concerns and experiences with neglect and abuse of $\mathrm{NH}$ residents, the participants believed that incidences of error, neglect and abuse were consequences of their own vulnerability, since they were not able to meet the demands of an overstrained work situation [61]. Employees' rudeness may not be actively premeditated but rather stems from work that is extremely stressful because of understaffing, a lack of time for individualized care, interpersonal conflicts, and aggression by certain residents or their relatives [21].

These underlying explanations lead to organizational and cultural explanations for elder abuse in NH. Findings from our study revealed that relatives mostly perceived organizational factors as decisive explanations.
These were factors such as low staffing, poor leadership, and a working culture characterized by fear and loyalty to employer or co-workers. According to the relative's perception of abuse and neglect being trivialized by the $\mathrm{NH}$ and of poor leadership, Myhre et al. found that the occurrence of abuse was rationalized in $\mathrm{NH}$, and care managers attempted to excuse why it was happening [60]. NH leaders did not have a clear perception of how they should follow up incidents of elder abuse on different levels in the organization and what their role should be in preventing elder abuse $[60,62]$.

Previous studies have shown that interactions resulting in abuse and neglect were more related to the care culture than being intentional by staff $[63,64]$. Furthermore, relatives in our study explained that resident-toresident aggression was caused by too few staff to look after the residents. Other studies have also connected resident-to-resident aggression to organizational factors such as staffing levels and mix and found it was largely normalized by the institutional context in which it occurred [47]. In addition, the physical environment contributed to resident-to-resident aggression [47], as it occurred in public areas such as dining rooms and hallways as well as in private areas such as a resident's private room [65].

Elder abuse has been conceptualized as a specific form of institutional abuse within $\mathrm{NH}$ in earlier studies [66]. NH may be seen as a setting in which abuse and neglect occur [21] since rules and regulations in institutions, such as mealtimes and sleeping time, may be considered abusive, and the shared living space with other residents constrains individualized care. Institutional abuse may be viewed as a lack of positive response to the complex needs of residents, rigid routines, inadequate staffing, and an insufficient knowledge base within the service [67]. Additionally, the chronosystem of the ecological model of elder abuse will have an impact on norms and values, such as becoming old and no longer being considered a useful member of the society, but rather a burden. Further, factors from the societal level will affect $\mathrm{NH}$ institutions through ageism and budgets. Rather than supporting the notion that abuse is perpetrated by a few wicked individuals per se, one must address flaws in the system instead, with less "blame" on individuals [68]. Determinants related to abuse within institutions are complex and multifactorial, entailing various associations between personal, social and organizational factors in addition to factors within the wider society $[25,69]$. This means that the risks of staff-to-resident abuse and resident-to-resident aggression extend beyond the traits and circumstances of staff who abuse or neglect the residents or the aggressive residents who harm them [25]. 


\section{Maltreatment of relatives to $\mathrm{NH}$ residents}

In this study, the relatives' stories demonstrated that they themselves were victims of maltreatment from the $\mathrm{NH}$. Their stories comprised co-suffering with their parent's or spouse's suffering, rejection and ignoration from staff, lack of involvement in the resident's situation, and staff who were directly hostile when a conflict had arisen. Relatives also felt that their cooperation occurred solely on the terms set by the $\mathrm{NH}$ or that they were given a role as a "troublesome" relative if they tried to interfere. Another study that explored staff-family relationships in $\mathrm{NH}$ had similar findings, where the relatives experienced lack of affirmation by the staff, that they were excluded from decision-making, were treated in an unfriendly manner, and gained no feedback from staff [43].

These experiences of maltreatment against relatives of $\mathrm{NH}$ residents have grave consequences. The relatives experienced stress and anxiety, and they were fearful of retaliation from staff towards their parent or spouse, which made relatives more inclined to accept negative $\mathrm{NH}$ practices. Furthermore, it made them compensate for lack of care. The key issue here is the lack of trust that emerges in the relationship between relatives and staff. A complicating factor in the description and understanding of elder abuse is that the voices of the older people themselves have generally been excluded [36]. In our study, relatives perceived themselves as important voices for their "voiceless" family member and were subsequently also worried for other residents who did not have relatives to speak for them. This perhaps speaks to the necessity of systematic, trust-based cooperation between relatives and staff. A key finding in a recent qualitative study of relatives and care staff collaboration was that staff and relatives together were able to identify factors of residents' well-being, and family members who visited daily worked collaboratively with care staff to maintain the quality of life of their relatives and engaged in proxy decision-making. The result was that they managed to avoid abuse [45]. Including the relatives in a symmetrical collaboration on the relative's own terms is therefore of utmost importance.

\section{Strengths and limitations}

This is a study of relatives' experiences with abuse and neglect of family members residing in $\mathrm{NH}$ and is therefore concerned with negative aspects of $\mathrm{NH}$ institutions. One limitation that should be acknowledged is participation bias [48]. Family members who volunteered to participate in this study were heavily involved in the issues raised by the study, as they had experienced abuse and neglect of their family member first-hand. A purposive sample was used to involve participants who were concerned more than usual about abuse and neglect in $\mathrm{NH}$.
In that way, they might enrich the data and thereby the knowledge about the phenomenon [50]. This study design may also result in an unbalanced representation of the reality in $\mathrm{NH}$. A more balanced representation could have been made if staff and residents themselves were also interviewed. However, staff experience with abuse and neglect have been described in several studies, both quantitative and qualitative $[3,5,11-13,20-22,24,27$, 30-32, 60]. Furthermore, as most residents are unable to represent experiences of abuse and neglect themselves, relatives become an important proxy, providing unique perspectives on a severe and difficult topic. It must however be stressed that they do not necessarily represent the exact experiences of the residents themselves.

All authors are registered nurses with $\mathrm{PhD}$ and have knowledge about $\mathrm{NH}$ through cooperation with $\mathrm{NH}$ in research and nursing student training for many years. The authors are currently working in academic professions, but also have work experience from NH. One of the authors have also worked as a NH leader. The authors have a shared interest in research regarding Quality of Care in older persons and elder abuse in various settings. This experience and knowledge provide significant contextual insight into the study phenomenon, but also entails a risk of prejudiced assumptions. We have therefore been conscious of our own preconceptions through the different steps of the research process.

In this study, we used telephone interviews due to the lockdown during the COVID-19 pandemic in the spring of 2020. During the planning phase, we perceived this as a limitation since we could not meet face-to-face and read the informants' facial expressions and body language [50]. However, we soon discovered telephone interviews to be an advantage. The informants all conversed with us from their home environment, which had a relaxing effect on informants when telling us about challenging experiences with abuse and neglect of loved ones. This is a sensitive topic, and experiences such as abuse and neglect of loved ones may be emotionally difficult to share. However, the informants were very open-hearted, and many interviews lasted much longer than scheduled due to the many experiences the informants wished to share with us.

The interviews engaged relatives with similar experiences of elder abuse in NH from all over Norway. During the data collection, we soon discovered similarities in their stories, and the analysis further confirmed this, which increases the value of these findings to other $\mathrm{NH}$ where abuse and neglect may occur. The findings from our study does not necessarily describe experiences that are common for all $\mathrm{NH}$ residents, but rather the nature of abused $\mathrm{NH}$ residents as experienced by the relatives. However, it is important to stress that relatives may have a wide range of experiences with $\mathrm{NH}$ that are not abuse, 
including experiences of low-quality care, but not clearly defined as abuse, as well as the experiences of good quality care. This is not expressed through a study such as ours, which investigates the problematic aspect of elder abuse in $\mathrm{NH}$ institutions. In order to achieve improvement in $\mathrm{NH}$ quality of care and prevent abuse and neglect, problematic areas of $\mathrm{NH}$ practice need to be addressed.

\section{Conclusions}

The current study concludes that relatives whose lovedone's experienced abuse or neglect experience all forms of elder abuse in $\mathrm{NH}$ as defined by the WHO, and that neglect of basic care and individual rights is predominant. The relatives viewed organizational explanations as most important and had seen consequences such as depression, anxiety and aggression when their loved ones were exposed to abuse and neglect. Relatives perceive themselves as collaborators in care and are emotionally attached to their family member. Therefore, experiencing resident abuse or neglect inflicts a feeling of being mistreated themselves, particularly if the relatives are not listened to, if their notice of abuse on the part of the resident is ignored or trivialized, or if they are left with a fear of retaliation from staff towards their family member. This reveals a deep distrust among relatives directed towards NH staff and organizations. This is unfortunate, as the relatives are an important link between residents' needs for individualized care and the nursing homes that are the ones to execute the care. Including relatives in a committed partnership with $\mathrm{NH}$ is not only a valuable path in the prevention of risk of abuse, but it also leads to a more sustainable healthcare with high standards of quality and safety.

\section{Abbreviations}

NFR: Research Council of Norway; NH: Nursing home; NKVTS: Norwegian Centre for Violence and Traumatic Stress Studies; NSD: Norwegian Centre for Research Data; NTNU: Norwegian University of Science and Technology; ADL: Activities of daily living

\section{Acknowledgements}

We would like to express our gratitude to the relatives who generously shared their experiences with elder abuse and neglect in nursing homes. Thanks also to the Norwegian Health Association, Norwegian alliance for informal carers and The Norwegian Pensioners' Association for sharing information on social media platforms to recruit participants.

\section{Authors' contributions}

SS, LEB, SN and AS developed the study design. SS, LEB and AS performed the interviews. SS and LEB performed the analyses of the interviews, with discussion including all authors. SS wrote the manuscript. All authors participated in critical revisions of the manuscript for important intellectual content, and all read and approved the final manuscript.

\section{Funding}

The study is funded by the Research Council of Norway (NFR), project number: 262697.

\section{Availability of data and materials}

The datasets generated and/or analysed during the current study are not publicly available due to individual privacy could be compromised but are available from the corresponding author on reasonable request.

\section{Declarations}

Ethics approval and consent to participate

Ethical approval for this study was given by the Norwegian Centre for Research Data (NSD), Registration No: 740981. Participants received oral and written information about the study prior to the interview and NSD approved that the participants could give an oral audiotaped consent to participate in the interviews and for the use of the data from the interviews. The study conducted is in accordance with the Declaration of Helsinki Ethical Principles and COREQ guidelines was used in the reporting of the qualitative study.

\section{Consent for publication}

The participants consented to the publication of de-identified material from. the interviews.

\section{Competing interests}

The authors declare that they have no competing interests.

\section{Author details}

${ }^{1}$ Department of Public Health and Nursing, Faculty of Medicine and Health Sciences NTNU, Norwegian University of Science and Technology,

Trondheim, Norway. ${ }^{2}$ Norwegian Centre for Violence and Traumatic Stress Studies, Oslo, Norway.

Received: 26 January 2021 Accepted: 29 June 2021

Published online: 11 July 2021

References

1. Havreng-Théry C, Giner-Perot J, Zawieja P, Bertin-Hugault F, Belmin J, Rothan-Tondeur M. Expectations and needs of families in nursing homes: an integrative review. Med Care Res Rev. 2020. https://doi.org/10.1177/1 077558720907183

2. Isola A, Backman K, Voutilainen P, Rautsiala T. Family members' experiences of the quality of geriatric care. Scand J Caring Sci. 2003;17(4):399-408. https://doi.org/10.1046/j.0283-9318.2003.00246.x.

3. Goergen T. A multi-method study on elder abuse and neglect in nursing homes. J Adult Prot. 2004;6(3):15-25. https://doi.org/10.1108/146682032004 00016.

4. Griffore RJ, Barboza GE, Mastin T, Oehmke J, Schiamberg LB, Post LA. Family members' reports of abuse in Michigan nursing homes. J Elder Abuse Negl. 2009:21(2):105-14. https://doi.org/10.1080/08946560902779910.

5. Natan MB, Lowenstein A. Study of factors that affect abuse of older people in nursing homes. Nurs Manag (Harrow). 2010;17(8):20-4. https://doi.org/10. 7748/nm2010.12.17.8.20.c8143.

6. Cohen M, Halevy-Levin S, Gagin R, Priltuzky D, Friedman G. Elder abuse in long-term care residences and the risk indicators. Ageing Soc. 2010; 30(6): 1027-1040. https://doi.org/10.1017/S0144686X10000188.

7. Bužgová R, Ivanová K. Violation of ethical principles in institutional care for older people. Nurs Ethics. 2011;18(1):64-78. https://doi.org/10.1177/0969733 010385529.

8. Zhang Z, Schiamberg LB, Oehmke J, Barboza GE, Griffore RJ, Post LA, et al. Neglect of older adults in Michigan nursing homes. J Elder Abuse Neg. 2011;23(1):58-74. https://doi.org/10.1080/08946566.2011.534708.

9. Habjanic A, Lahe D. Are frail older people less exposed to abuse in nursing homes as compared to community-based settings? Statistical analysis of Slovenian data. Arch Gerontol Geriatr. 2012;54(3):e261-70. https://doi.org/1 0.1016/j.archger.2011.07.006

10. Drennan J, Lafferty A, Treacy MP, Fealy G, Phelan A, Lyons I, et al. Older people in residential care settings: results of a national survey of staffresident interactions and conflicts. Dublin: NCPOP, University College Dublin; 2012.

11. Malmedal W, Ingebrigtsen $O$, Saveman BI. Inadequate care in Norwegian nursing homes - as reported by nursing staff. Scand J Caring Sci. 2009;23(2): 231-42. https://doi.org/10.1111/j.1471-6712.2008.00611.x. 
12. Botngård $A$, Eide $A H$, Mosqueda L, Malmedal W. Elder abuse in Norwegian nursing homes: a cross-sectional exploratory study. BMC Health Serv Res. 2020;20:9. https://doi.org/10.1186/s12913-019-4861-z.

13. Botngård A, Eide AH, Mosqueda L, Malmedal W. Resident-to-resident aggression in Norwegian nursing homes: a cross-sectional exploratory study. BMC Geriatr. 2020;20:222. https://doi.org/10.1186/s12877-020-01623-7.

14. Mikton CR, Butchard A, Dahlberg LL, Krug EG. Global status report on violence prevention 2014. Am J Prev Med. 2016;50(5):652-9.

15. Yunus RM, Hairi NN, Choo WY. Consequences of Elder Abuse and Neglect: A Systematic Review of Observational Studies. Trauma Violence Abuse. 2019;20(2):197-213. https://doi.org/10.1177/1524838017692798.

16. Baker M. Elder mistreatment: risk, vulnerability, and early mortality. Am Psychiatr Nurs Assoc. 2007;12(6):313-21.

17. Justis- og beredskapsdepartementet. Meld. St. 15 (2012-2013) Forebygging og bekjempelse av vold i nære relasjoner [White Paper No. 15 (2012-2013) Prevention and combating of violence in close relationships]. Oslo: Justisog beredskapsdepartementet [Ministry of Justice and Public Security); 2013.

18. World Health Organization. The Toronto Declaration on the Global Prevention of Elder Abuse. Geneva: World Health Organization; 2002. http://apps.who.int/iris/bitstream/10665/42495/1/9241545615_eng.pdf. Accessed 13 Nov 2020

19. World Health Organization. World report on violence and health: Summary. Geneva: World Health Organization; 2002. https://www.who.int/violence injury_prevention/violence/world_report/en/summary_en.pdf. Accessed 13 Nov 2020

20. Yon Y, Ramiro-Gonzalez M, Mikton CR, Huber M, Sethi D. The prevalence of elder abuse in institutional settings: a systematic review and meta-analysis. Eur J Pub Health. 2019;29(1):58-67. https://doi.org/10.1093/eurpub/cky093.

21. Bužgová R, Ivanová K. Elder abuse and mistreatment in residential settings. Nurs Ethics. 2009;16(1):110-26. https://doi.org/10.1177/0969733008097996.

22. Lachs MS, Teresi JA, Ramirez M, van Haitsma K, Silver S, Eimicke JP, et al. The prevalence of resident-to-resident elder mistreatment in nursing homes. Ann Intern Med. 2016;165(4):229-36. https://doi.org/10.7326/M15-1209.

23. Rosen T, Pillemer K, Lachs M. Resident-to-resident aggression in long-term care facilities: an understudied problem. Aggress Violent Behav. 2008;13(2): 77-87. https://doi.org/10.1016/j.avb.2007.12.001.

24. Pillemer K, Chen EK, Van Haitsma KS, Teresi J, Ramirez M, Silver S, et al. Resident-to-resident aggression in nursing homes: results from a qualitative event reconstruction study. Gerontologist. 2012;52(1):24-33. https://doi.org/1 0.1093/geront/gnr107.

25. Schiamberg LB, Barboza GG, Oehmke J, Zhang Z, Griffore RJ, Weatherill RP, et al. Elder abuse in nursing homes: an ecological perspective. J Elder Abuse Neglect. 2011;23(2):190-211. https://doi.org/10.1080/08946566.2011.558798.

26. Dong XQ. Elder abuse: systematic review and implications for practice. J Am Geriatr Soc. 2015;63(6):1214-38

27. Wang JJ. Psychological abuse behavior exhibited by caregivers in the care of the elderly and correlated factors in long-term care facilities in Taiwan. Nurs Res. 2005;13(4):271-80.

28. Gorbi G, Grattagliano I, Ivshina E, Ferrara N, Solimeno Cipriano A, Campobasso CP. Elderly abuse: risk factors and nursing role. Intern Emerg Med. 2015;10:297-303. https://doi.org/10.1007/s11739-014-1126-z.

29. Kamavarapu YS, Ferriter M, Morton S, Völlm B. Institutional abuse characteristics of victims, perpetrators and organisations: a systematic review. Eur Psychiatry. 2017;40:45-54. https://doi.org/10.1016/j.eurpsy.2016. 07.002 .

30. McCool JJ, Jogerst GJ, Daly JM, Xu Y. Multidisciplinary reports of nursing home mistreatment. J Am Med Dir Assoc. 2009;10(3):174-80. https://doi. org/10.1016/j.jamda.2008.09.005.

31. Wang JJ, Lin MF, Tseng HF, Chang WY. Caregiver factors contributing to psychological elder abuse behavior in long-term care facilities: a structural equation model approach. Int Psychogeriatr. 2009;21(2):314-20. https://doi. org/10.1017/S1041610208008211.

32. Malmedal W, Hammervold R, Saveman Bl. The dark side of Norwegian nursing homes: factors influencing inadequate care. J Adult Protect. 2014; 16(3):133-51. https://doi.org/10.1108/JAP-02-2013-0004.

33. Castle NG, Engberg J. Organizational characteristics associated with staff turnover in nursing homes. Gerontologist. 2006;46(1):62-73. https://doi.org/1 0.1093/geront/46.1.62.

34. Gautun $\mathrm{H}$. En utvikling som må snus. Bemanning og kompetanse i sykehjem og hjemmesykepleien [A development that must be reversed. Staffing and competence in nursing homes and home nursing]. NOVA,
OsloMet. 2020. https://fagarkivet-hioa.archive.knowledgearc.net/bitstream/ha ndle/20.500.12199/6417/NOVA-Rapport-14-20\%20.pdf?sequence=6\&isA llowed=y. Accessed 13 Nov 2020.

35. Lafferty A, Treacy MP, Fealy G, Drennan J, Lyons I. Older people's experiences of mistreatment and abuse. Dublin: NCPOP, University College; 2012. https://www.hse.ie/eng/services/publications/olderpeople/mistrea tementandabuse.pdf. Accessed 11 Nov 2020

36. World Health Organization. Missing Voices; Views of Older Persons on Elder Abuse. 2002. https://www.who.int/ageing/publications/missing_voices/en/. Accessed 18 Nov 2020.

37. Erlingsson $\mathrm{CL}$, Saveman Bl, Berg AC. Perceptions of elder abuse in Sweden: voices of older persons. Brief Treat Crisis Interv. 2005;5:213-27. https://doi. org/10.1093/brief-treatment/mhi017.

38. Statistisk Sentralbyrå [Statistics Norway]. Nøkkeltall for helse I Norge [Key numbers related to health care in Norway]. 2019. https://www.ssb.no/helse/ nokkeltall. Accessed 11 Nov 2020

39. Ågotnes $\mathrm{G}$. The Institutional Practice. On nursing homes and hospitalizations. Oslo: Cappelen Damm Akademisk; 2017.

40. Helse- og omsorgsdepartementet [Ministry of Health and Care Service]. Lov om kommunale helse- og omsorgstjenester m.m. [Act of municipal health and care services]. SS: https://lovdata.no/dokument/NL/lov/2011-06-24-30. Accessed 3 Dec 2020.

41. Harnett $\mathrm{T}$, Jönson $\mathrm{H}$. That's not my Robert! Identity maintenance and other warrants in family members' claims about mistreatment in old-age care. Ageing Soc. 2010;30(4):627-47. https://doi.org/10.1017/S0144686X09990584.

42. Post L, Page C, Conner T, Prokhorov A, Fang Y, Biroscak BJ. Elder abuse in long-term care: types, patterns, and risk factors. Res Aging. 2010;32(3):32348. https://doi.org/10.1177/0164027509357705.

43. Friedemann ML, Montgomery RJ, Maiberger B, Smith AA. Family involvement in the nursing home: family-oriented practices and staff-family relationships. Res Nurs Health. 1997;20(6):527-37. https://doi.org/10.1002/ (sici)1098-240x(199712)20:6<527::aid-nur7>3.0.co;2-o.

44. Gjerberg E, Lillemoen L, Pedersen R, Førde R. Coercion in nursing homes: perspectives of patients and relatives. Nurs Ethics. 2016;23(3):253-64. https:// doi.org/10.1177/0969733014564907.

45. Hughes SE, Woods B, Algar-Skaife $\mathrm{K}$, Jelley $\mathrm{H}$, Jones CJ. A collaborative approach: care staff and families working together to safeguard the quality of life of residents living with advanced dementia. J Central Nervous Syst Dis. 2019;11:1-9. https://doi.org/10.1177/1179573519843872.

46. Bolt SR, Verbeek L, Meijers JMM, van der Steen JT. Families' experiences with end-of-life Care in Nursing Homes and Associations with Dying Peacefully with Dementia. J Am Med Dir Assoc. 2019;20(3):268-72. https://doi.org/10.1 016/j.jamda.2018.12.001

47. Baumbusch J, Puurveen G, Phinney A, Beaton MD, Leblanc ME. Family members' experiences and management of resident-to-resident abuse in long-term residential care. J Elder Abuse Neglect. 2018;30(5):385-401. https://doi.org/10.1080/08946566.2018.1518179.

48. Malterud K. Kvalitative forskningsmetoder for medisin og helsefag. 4th. ed Oslo: Universitetsforlaget; 2017.

49. Saunders B, Sim J, Kingstone T, Baker S, Waterfield J, Bartlam B, et al. Saturation in qualitative research: exploring its conceptualization and operationalization. Qual Quant. 2018;52(4):1893-907. https://doi.org/10.1007/s11135-017-0574-8.

50. Polit DF, Beck $C T$. Nursing research: generating and assessing evidence for nursing practice. 10th ed. Philadelphia: Wolters Kluwer Health/Lippincott Williams \& Wilkins; 2016.

51. Graneheim UH, Lundman B. Qualitative content analysis in nursing research: concepts, procedures and measures to achieve trustworthiness. Nurse Educ Today. 2004;24(2):105-12. https://doi.org/10.1016/j.nedt.2003.10.001.

52. Graneheim UH, Lindgren BM, Lundman B. Methodological challenges in qualitative content analysis: a discussion paper nurse education today; 2017; 56:29-34. https://doi.org/10.1016/j.nedt.2017.06.002.

53. Phelan A. Elder abuse and neglect: the nurse's responsibility in care of the older person. Int J Older People Nursing. 2009;2(4):115-9. https://doi.org/1 0.1111/j.1748-3743.2009.000164.x.

54. Kalisch B. Missed nursing care: a qualitative study. J Nurs Care Qual. 2006; 21(4):306-13. https://doi.org/10.1097/00001786-200610000-00006.

55. Kalisch BJ, Landstrom G, Williams RA. Missed nursing care: errors of omission. Nurs Outlook. 2009;57(1):3-9. https://doi.org/10.1016/j.outlook.2008.05.007.

56. O'Neill D. Leas cross review. Dublind: Health Service Executive; 2006. https:// www.hse.ie/eng/services/publications/olderpeople/leas-cross-report-.pdf. Accessed 11 Nov 2020 
57. Stevens M, Biggs S, Dixon J, Tinker A, Manthorpe J. Interactional perspectives on the mistreatment of older and vulnerable people in longterm care settings. Br J Sociol. 2013;64(2):267-86. https://doi.org/10.1111/14 68-4446.12017.

58. Teeri S, Välimäki M, Katajisto J, Leino-Kilpi H. Nurses perceptions of older patients' integrity in long-term institutions. Scand J Caring Sci. 2007;21(4): 490-9. https://doi.org/10.1111/j.1471-6712.2007.00499.x.

59. Oosterveld-Flug MG, Onwuteaka-Philipsen BD, Pasman HRW, van Gennip IE, de Vet HCV. Can personal dignity be assessed by others? A survey study comparing nursing home residents' with family members', nurses' and physicians' answer on the MIDAM-LTC. Int J Nurs Stud. 2015;52(2):555-67. https://doi.org/10.1016/j.jijurstu.2014.06.007.

60. Myhre J, Saga S, Malmedal WK, Ostaszkiewicz J, Nakrem S. Elder abuse and neglect: an overlooked patient safety issue. A focus group study of nursing home leaders' perceptions of elder abuse and neglect. BMC Health Serv Res. 2020;20:199. https://doi.org/10.1186/s12913-020-5047-4.

61. Nordström K, Wangmo T. Caring for elder patients: mutual vulnerabilities in professional ethics. Nurs Ethics. 2018;25(8):1004-16. https://doi.org/10.1177/ 0969733016684548.

62. Myhre J, Saga S, Malmedal WK, Ostaszkiewicz J, Nakrem S. React and act; A qualitative study of how nursing home leaders follow up on staff-toresident abuse. BMC Health Serv Res. 2020;20:1111. https://doi.org/10.1186/ s12913-020-05969-x.

63. Kitwood T. Dementia reconsidered: The person comes first. Buckingham: Open University Press; 1997.

64. Pickering CEZ, Nurenberg K, Schiamberg L. Recognizing and responding to the "toxic" work environment: worker safety, patient safety, and abuse/ neglect in nursing homes. Qual Health Res. 2017;27(12):1870-81. https://doi. org/10.1177/1049732317723889.

65. Rosen T, Lachs MS, Bharucha AJ, Stevens SM, Teresi JA, Nebres F, et al. Resident-to-resident aggression in long-term care facilities: insights from focus groups of nursing home residents and staff. J Am Geriatr Soc. 2008; 56(8):1398-408. https://doi.org/10.1111/j.1532-5415.2008.01808.x.

66. Nerenberg L. Elder abuse prevention: emerging trends and promising strategies. New York: Springer Publishing Company; 2007.

67. Dunn P. No secrets: guidance on developing and implementing multiagency policies and procedures to protect vulnerable adults from abuse: Department of Health; 2000.

68. Burns D, Hyde P, Killett A. Wicked problems or wicked people? Reconceptualising institutional abuse. Sociol Health Illness. 2012;35(4):51428. https://doi.org/10.1111/j.1467-9566.2012.01511.x.

69. McDonald L, Beaulieu M, Harbison J, Hirst S, Lowenstein A, Podnieks E, et al. Institutional abuse of older adults: what we know, what we need to know. $J$ Elder Abuse Neglect. 2012;24(2):138-60. https://doi.org/10.1080/08946566.2 011.646512 .

\section{Publisher's Note}

Springer Nature remains neutral with regard to jurisdictional claims in published maps and institutional affiliations.

\section{Ready to submit your research? Choose BMC and benefit from:}

- fast, convenient online submission

- thorough peer review by experienced researchers in your field

- rapid publication on acceptance

- support for research data, including large and complex data types

- gold Open Access which fosters wider collaboration and increased citations

- maximum visibility for your research: over $100 \mathrm{M}$ website views per year

At $\mathrm{BMC}$, research is always in progress.

Learn more biomedcentral.com/submissions 